\title{
The Biology of Armillaria mucida, Schrader.
}

\author{
BY
}

\section{E. C. FISCHER,}

Indian Forest Service.

\section{With Plates XXXVII and XXXVIIT.}

A RMILLARIA MUCIDA is a widely distributed gill-fungus wherever the beech occurs. Saccardo (23) gives its habitat as '... totius Europae et Americanae federatae, frequens,' and according to McIlvaine (16) its distribution in America extends to the States of North Carolina, Pennsylvania, and West Virginia.

There appears to be no special literature on the subject of this plant, and a perusal of the references to it in textbooks and floras leaves some doubt in the mind as to whether it should be described as a parasite of the beech or as a saprophyte on dead beech wood. Generally speaking, we may take it that the older works treat it as a saprophyte and more recent ones as a parasite, as will be seen from a perusal of the following extracts.

Schrader, I794 (24), says : 'Hab. ad Fagos emortuas'; Fries, I82I (10): 'In truncis vetustis, apprime Fagi'; Patouillard in I886 (19) gave: '... sur les troncs pourris'; Lambotte (13) has : ' . . parmi le gazon, sur les racines ou sur les troncs coupés du hêtre.'

On the other hand, we have Massee's account (15) of a successful infection: 'At High Beech, Epping Forest, . . . a healthy branch of a beech having been broken off, the wound was inoculated with the spores of A. mucida. At the end of the second season after the inoculation the branch was killed for a considerable distance, and the sporophores of the fungus appeared in abundance. The spores also germinate readily on very small wounds made in the bark.'

It is obvious that sufficient information has not been given, and in the absence of statement to the contrary we are justified in believing that no precautions were taken to exclude infection by other fungi. Some parasitic ungus, e.g. Polyporus fomentarius, may have gained entry and prepared the way for $A$. mucida by killing the tissues.

Cooke (6), in 1906, wrote of this same fungus : '... so commonly seen on beech trees... has been charged with being a wound parasite, capable

[Annals of Botany, Vo1. XXIII. No. XCII. October, 1909.] 
of atticking a healthy branch when broken or wounded and causing death and decay.' This statement is probably inspired by Massee's report quoted above. Sorauer, in 1906 (25), also evidently accorded it parasitic rank, since he refers to it in his work: 'Von der Gattung Armillaria wäre in erster Linie A. mucida zu erwähnen,' but he adds: '.. über die Art des Parasitismus wissen wir nichts.' Finally, we have the following authors who make no reference to it as a parasite: Tubeuf (26), Prillieux (21), and Frank (9) omit all mention of it ; Saccardo (23) states: 'Hab. ad truncos Fagi'; Gillot and Lucaud, I89I (12): ' . . exclusivement sur les vieux troncs de hêtres'; Gautier (11), in I 884 : ' $\ldots$ sur les troncs de hêtres languissants ou coupés depuis peu'; McIlvaine (16): ' $\ldots$ on beech trees and roots ... pushing up through the soil' ; Rabenhorst (22): 'An Buchenstangen.'

It seems, therefore, highly desirable that further tests be applied to determine whether the fungus is a parasite or a saprophyte. The experiments described later clearly demonstrate that it can attack dead beech wood, but so far give no evidence of a true parasitic nature. However, let me at once admit that my experiments were neither sufficiently numerous nor extended over a sufficient space of time to traverse the theory of parasitism. Indeed, I am far from claiming to have proved that Armillaria mucida is not a parasite, but I am of opinion that more evidence, and of a positive character, is required before we accept that view. It is true that perfectly healthy trees in full vigour bear branches from which the fructifications of this fungus extrude, but in all cases the tissues in the neighbourhood of the tufts of carpophores are dead, and this is also the case when the tufts are seated on diseased parts of the main trunk itself. It should not be forgotten, moreover, that our knowledge of the causes predisposing to disease is almost negligible. Buller (4) failed to infect living maple and horse-chestnut trees with the spores of Polyporus squamosus, and in his paper remarks: "Possibly in nature other organisms serve to prepare the wounds for infection by the fungus.' This 'preparation ' might be the killing of the tissues in advance of the fungus under consideration, which then would be an obligate saprophyte and no longer even a facultative parasite. This should be borne in mind in connexion with Massee's account of his experiment commented on earlier. This point will be dealt with further when we come to discuss the results of the inoculation experiments.

\section{DESCRIPTION OF THE FUNGUS.}

A description of the fruit body of $A$. mucida will not be out of place, and the following is compiled from those of Cooke (5) and Massee (14):-

Pileus I to 4 inches across, flesh thin and almost diaphanous, hemispherical, then expanded, obtuse, often rugulose; glutinous, whitish or tinged with grey (by some authors described as often much darker); often 
growing in clusters (Pl. XXXVII, Figs. 1 and 2); gills white, rounded behind, and broadly adnexed with a line-like decurrent tooth; stipe 2 to 5 inches long, rather slender, but thickened at the base ; white, but base often with sooty squamules, rigid, stuffed; ring near apex of stipe, white tumid; spores elliptical, very shiny, I 4 to 16 by 8 to $9 \mu$.

Massee adds: "Very variable in size. Readily known by the very shiny pileus, which is usually whitish, but sometimes sooty or olive brown. Solitary or caespitose.'

It may be added that there are three vulgar names for this fungus in England: 'Beech Tuft,' 'Beech Agaric,' and 'Clammy Armillaria.'

The descriptions by all other authors that I have consulted agree with that given above, with the exception of the statement as to the shape of the spores. Brefeld (2) refers to them as '... fast runden Sporen,' and Patouillard (19) figures them spherical or nearly so. This discrepancy is to be explained in the same way as Münch settled the controversy between Möller and Malenconvié as to the shape of the spores of Merulius lachrymans (17). Münch showed that those spores when quite dry are collapsed and boat-shaped, but swell out when moistened, though only by the breath, to an oval outline. I find the same phenomenon in the case of $A$. mucida, and that when moist the spores are almost perfectly spherical with a small insertion papilla and granular contents (Figs. 3 and 4), with an average diameter of $14 \mu$. The utility of this adaptation for dispersal is obvious, for the convexity when dry, coupled with the lightness due to absence of water, gives a better prospect of transport by wind. Dr. Münch himself showed me a similar process with the spores of other fungi, among them one or two Ascomycetes. It seems probable that it occurs in most, if not all, fungi with smooth-walled spores that depend on wind for dispersal.

\section{SubJect OF THE INVESTigation.}

The object of this inquiry was threefold :-

I. To trace out the life-history of the fungus, at the same time determining its true nature-parasitic or saprophytic.

2. To investigate its action on the wood.

3. To suggest appropriate preventive and remedial measures.

Each of these three will be dealt with separately and in the above order.

\section{LifE-History.}

Methods.-The fruit bodies from which all the cultures were started were obtained from beech trees in Windsor Park on November 18 and 27, 1908. On the second occasion I took a sterilized Petri-dish with me, and one sporophore was placed directly in it. The spores shed on the 


\section{Fischer.-The Biology of Armillariu mucida, Schrader.}

bottom of the dish were used for starting cultures, as also were spores obtained in a similar way in the laboratory from the carpophores brought in on the first occasion. These spores were taken off with a sterilized needle and inoculated into nutritive media.

Some of the cultures were started by means of a neat contrivance invented by Dr. Münch and described by him in his inaugural dissertation (18). A piece of cloth (velvet is very suitable) with a circular hole cut out of its centre, of a smaller diameter than the mouth of the vessel that is to contain the culture, is sewn on to a piece of wire mesh. It is best to cut the cloth so as to allow a sufficient overlap to fold back and cover any object that is placed on the wire.

The stipe is cut off a carpophore and after testing it to make sure that it is actively shedding its spores, the cap is deposited on the wire net in such a position that a portion shedding spores comes directly over the hole in the cloth. The whole is thoroughly wetted, and the superfluous moisture is vigorously shaken out in order to avoid any flow of water. With one hand the vessel containing the culture solution is opened, and the wire net with the cap is slipped on with the other with the least possible interval, and is so fitted that the hole in the cloth coincides with the mouth of the vessel. After the lapse of a few minutes, long enough to allow of the deposition of a sufficient number of spores, but not for the drying up of the cloth, the apparatus is removed and the stopper slipped back with the same caution as before. As long as the apparatus is thoroughly damp it is only the spores that are thrown off by the fungus and which pass through the meshes without touching the wire that can fall on the nutritive solution. All spores that touch the damp wire, including foreign ones that may have been previously adhering to any part of it or to the cap, will stick to it and will not fall through. It will be seen that in this way one can secure, practically with certainty, and without previous tedious separate eliminating cultures, a quite pure culture. Dr. Münch has employed this method with practically unfailing success in the course of many hundreds of pure cultures, and I have also obtained good results with it on a smaller scale. Dr. Münch, however, will be the first to agree that its results must not be accepted uncorroborated by other cultures started in other ways. Of course, this appliance can only be used with fungi which throw off their spores more or less violently.

The culture solutions employed were the following :-

For observation of the germination of the spores: hanging drops in moist chambers of prune juice, beer-wort jelly, sterilized water, and meat and malt extract jelly.

For observation of the development of the mycelium and as a source from which to obtain other cultures by inoculation: Petri-dishes containing beer-wort jelly and meat and malt extract jelly. 
Finally, for the permanent cultures in which the life-history was to be traced, the substratum used was chiefly bread moistened with water only, or with a decoction of horse-dung. Beech twigs and small cubes of beech wood were also made use of.

The permanent cultures were in bulb or Erlenmeyer flasks.

All glass receptacles were sterilized in the dry oven up to a temperature of $165^{\circ} \mathrm{C}$. Bread and beech twigs or cubes were similarly heated in the dry oven, the bread until it was toasted a rich brown, and subsequently moistened.

Liquids were placed in the steam sterilizer for at least one hour after strong steaming had begun on not less than three consecutive days. In addition, in order to exclude bacteria, a little acid was added to the liquids.

The manual methods employed do not essentially differ from those advocated by Brefeld (3), so they need not be described in detail. It will be sufficient to add that I took every care to avoid intrusion by foreign bodies and to keep the cultures absolutely pure. Cultures in which impurities-Bacteria, Penicillium, Mucor-appeared were promptly destroyed. The flasks were stoppered with cotton-wool, which was invariably burnt in a Bunsen flame before removing from or replacing in the mouth of a flask. The interior of the neck of the flask was similarly subjected to the Bunsen flame.

Altogether the following cultures were instituted: 8 hanging drops in moist chambers; 25 Petri-dish cultures in jelly; 12 on jelly or liquids in flasks; 6 on twigs or wood cubes; 2 on bread in large crystallizing dishes under bell-jars ; 23 in flasks on bread; and 4 in liquids in test-tubes.

The meat and malt extract jelly was made up as recommended by Professor von Tubeuf as follows :-

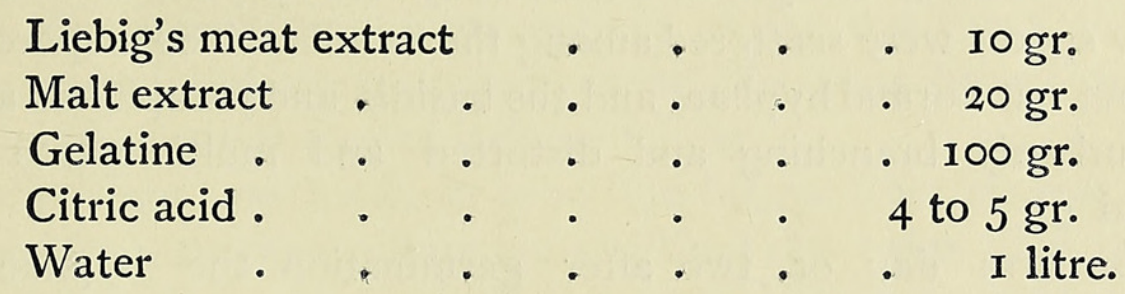

In some cases a decoction of horse-dung was added to the above, both with and without the gelatine.

Two other solutions were made up as follows :-

I. Peptone . . . . . . .25 gr.

Dextrose . . . . . . $125 \mathrm{gr}$.

Potassium phosphate. . . , .075 gr.

Magnesium sulphate . . . . $.005 \mathrm{gr}$.

Citric acid . . . . . I gr.

Water . . . $250 \mathrm{cc}$. 
II. Ammonium nitrate . . . . . $2.5 \mathrm{gr}$

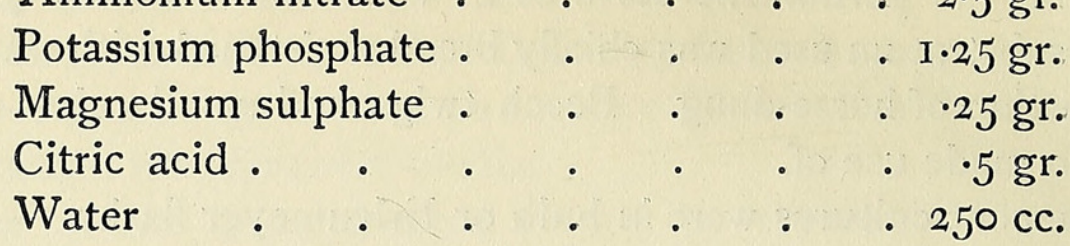

These were used either as jelly, when 25 gr. of gelatine were added, or in the liquid form.

The permanent cultures were started either by sowing the spores directly on the substratum or by inoculation from other obviously pure cultures.

\section{Germination and Subsequent Growth.}

In hanging drops of pure water, prune extract, or beer-wort jelly, as well as in Petri-dishes in beer-wort jelly, the spores germinated abundantly and at once, i. e. in less than twenty-four hours. Placed in the solution one morning they were found with germ-tubes on the following morning, twenty-one hours later. No germ-pore was to be distinguished in the spore-wall, and the germ-tube did not emerge at any fixed point, but in varying positions on the several spores. Prior to germination the spores became vacuolated. On germination the vacuoles enlarge, and the protoplasmic contents of the spore pass into the germ-tube (Fig. 6). The protoplasm advances with the end of the hypha, which becomes septate and empty behind. The hyphae produced in pure water, however, formed few septa.

In addition to spores small pieces from the interior of the stipe and the cap of a sporophore were placed on jelly in a Petri-dish. New growth of hyphae appeared from both in two days (Fig. 7).

A small section of the gill of a fruit body was suspended in a hanging drop ; a few spores were scattered among the basidia. These spores germinated and put out normal hyphae, and the basidia and paraphyses also grew out into curiously branching and distorted and multi-septate hyphae (Figs. 8 and 9).

For the first day or two after germination the hyphae remain unbranched, but then fork and ramify rapidly. The hyphae often fuse at the points of contact. There is a marked contrast in the habit of growth when there is sufficiency or deficiency of moisture. In the first case the hyphae are thick, long, and but little branched; when too dry they remain fine, shorter, and much branched (Figs. 10 and II). The hyphae often assume somewhat fantastic shapes: abruptly and angularly branched (Fig. I2), or, on the contrary, gracefully curled (Fig. I3).

In the Petri-dishes the mycelium soon showed above the surface of the jelly as a perfectly white felt, which spread rapidly till it covered the whole surface. In course of time, about twenty-five days, the mycelium 
assumed an orange hue underneath. Here, as well as in the cultures on jelly in flasks, the jelly was soon liquefied, showing that the fungus exudes some enzyme capable of liquefying gelatine. No crystals were formed as occurs with Cordyceps in jelly.

In most of the cultures clamp-connexions appeared on the hyphae (Figs. 14 and I5), in some cases in abundance. They were also seen in the stipe of a carpophore grown in pure culture, and in one case on a hypha in a wood vessel. This traverses Brefeld's assertion: ' . . ohne Schnallen...' (2).

No further changes were observable in any of the jelly cultures, whether in dishes or in flasks, or in hanging drops, or in any of the fluids experimented with. No fruit bodies or reproductive organs of any kind presented themselves. It would seem, therefore, that $A$. mucida is devoid of all form of conidia, a conclusion not altogether unexpected. In one rather doubtful case, in a hanging drop of water, something recalling oidia formation took place. The chamber had been allowed to dry and was nearly devoid of moisture, and the hyphae broke up into short lengths. This, however, was in one corner only, and I was unable to separate the short rods and test them for germinative power. Though I attach no importance to the occurrence, the fact is here stated for what it is worth. The rods are delineated in Fig. 16.

Attempts were made to stimulate the mycelium to produce conidia by altering the nutriment, but in vain. The amount of moisture, too, was varied; in one case the mycelium being allowed eventually to dry up altogether. The kind and quantity of acid was changed, lactic, gallic, and even oxalic acid being tried. With 0.4 per cent. of the last named the fungus grew just as well as in any of the other solutions.

Spores were also sown in the liquid solutions detailed previously. Though they gravitated to the bottom of the test-tubes, they nevertheless germinated, and the mycelium eventually made its way to the surface of the liquid, where it formed a dense felting.

An attempt was made to grow the fungus from spores, and also the mycelium from another culture, on sterilized elm twigs. No infection took place in spite of repetition, which apparently indicates considerable specialization in favour of beech.

As already stated no difficulty was met with in the germination of the spores when fresh. Some observations were made with regard to the endurance of germinative power. A cap obtained from a beech tree in Windsor Park was placed in a sterilized Petri-dish on November 20, and spores were shed on it, after which the cap itself was removed. The spores in the dish were kept quite dry, and were tested from time to time. By December 29 they had suffered already, for they no longer germinated at once, but took ten days to produce germ-tubes. Spores sown in fluid on 


\section{Fischer. - The Biology of Armillaria mucida, Schrader.}

January 5 germinated in a similar period, but in this case it was obviously difficult to make certain of germination at once on occurrence. Sown on the same solution with gelatine added on January 6 they failed altogether to germinate. But on the next day spores were sown on a jelly of meat and malt extract mixed with a decoction of horse-dung and acidulated with oxalic acid, and these germinated in ten days. Attempts made with spores from the same source at later dates were entirely unsuccessful.

This indicates no great endurance of germinative power, and as the fruit bodies ripen from August to December, infection must take place in autumn and the first half of winter; in other words, at a time when there is least sap in the host tree.

The spores formed on the carpophores grown in pure culture (as described later on) were slightly smaller than those found in nature, having an average diameter of 12 to $\mathrm{I} 3 \mu$ as against $14 \mu$ (Fig. 5). They germinated readily in water and in meat and malt jelly within twenty-four hours when fresh. These spores kept in a dry Petri-dish failed to germinate when four months old.

From the jelly cultures single germinated spores and pieces of mycelium were taken to start the permanent cultures on bread.

On the surface of the dense felted mycelium, both on bread and on jelly, beads of a clear brown fluid appeared.

On bread and on wood the fungus first showed itself in the shape of erect white flocculent hyphae about $\frac{1}{4}$ inch long. These soon became denser and formed a thick layer of perfectly white felted mycelium.

Pieces of mycelium grown on bread were found to be capable of further development on a jelly made with 12 per cent. gelatine and pure water, the jelly being liquefied in a few days. Also, in a solution of 20 per cent. glucose, both fluid and in a jelly with I 2 per cent. gelatine, similarly inoculated mycelium grew on actively, liquefying the jelly as before.

\section{SPOROPHORES.}

We will now follow the development of the fruit bodies in the cultures.

On November 28 a culture was started in an Erlenmeyer flask on beer-wort jelly by Münch's method of direct sowing described above. By the 3 oth of the same month it was evident to the naked eye that germination had taken place, and by December 24 the whole surface of the jelly was covered with a film of white mycelium. On that date a very small piece of mycelium was extracted and placed in another flask on bread moistened with a decoction of horse-dung acidulated with gallic acid. In two days it became obvious that the inoculation had been successful, and in a few days the white mycelium completely concealed the bread. On January 27 the first signs of fructification appeared, and eight days later the first sporophore attained maturity. Thus from germination of the 
spore to the first visible signs of fruiting sixty days elapsed, and in sixtyeight days the life-cycle had been accomplished.

In another flask, on December I5, on bread moistened with sterilized water only, spores were deposited with a needle. The first incipient carpophores showed themselves on January 29. Six days later there was a fully developed fruit body. So that in this case the generation occupied only fifty-eight days.

In other cultures fruit bodies also appeared, but only one more will be specially mentioned here.

Cubes of beech wood were sterilized in the dry oven at a temperature of $165^{\circ} \mathrm{C}$. They were inoculated on December 2I with a piece of mycelium taken from a culture in a Petri-dish on a jelly of meat and malt extract with agar. In two days a growth of flocculent white mycelium appeared around the inoculated section. This spread rapidly and covered the surfaces of all the blocks and bound them firmly together. After some time the mycelium in places assumed the orange hue already referred to in connexion with the Petri-dish cultures, and finally, after about five months, became blood-red in patches. Four carpophores arose in this flask, the first appearing on March 10 . This gives 79 days from the inoculation, and rog days from spore to spore. In this case the fruit bodies stood singly and not in clusters as is usual.

In order to ascertain the effect of desiccation on the mycelium, three pieces from the culture in which fructifications appeared on January 29 were taken out on the 27 th (i. e. before any signs of fruiting had shown themselves) and were placed in an empty sterilized flask. Twelve days later several incipient fruit bodies were to be seen on each fragment. They were unable, however, to grow further and mature, apparently owing to insufficient nutriment. This seems to indicate that when the mycelium as a whole has reached the fruiting-stage it acquires a stimulus to form fruit bodies, which asserts itself under comparatively adverse conditions.

So as to give them more food the three pieces were eventually transferred on to a jelly of meat and malt extract. In a few days they all three started vigorous vegetative growth, and the jelly was soon completely liquefied. Though the whole surface became covered with mycelium, the incipient sporophores did not develop, but, on the contrary, gradually disappeared, and no signs of new ones presented themselves during the four months for which the culture was kept on. This, coupled with the fact that no fructification ever came up on any of the cultures on jelly, seems to show that such a substratum cannot afford the conditions necessary for the production of fruit bodies. No experiment, however, was carried out with more concentrated solutions than those described in the formulae.

The earliest traces of the carpophores are recognizable as diminutive conical protuberances above the surface of the felted mycelium (Fig. I7). 
Usually these arise in clusters of a large number of individuals crowded together. In twenty-four hours, in vigorous growths, a small cap is already differentiated, the protuberances having elongated appreciably (Fig. I8). The increase in size and bulk goes on rapidly, and in three or four days the cap presents a very definite and separate structure; the veil is already stretched out and transparent, allowing the gills to be seen through it (Figs. I9 to 22). In another two or three days the veil has separated off altogether from the edge of the pileus, which then begins to expand, first to a horizontal position, and finally its edges curl up so that the lamellae are exposed laterally (P1. XXXVIII, Figs. 23 and 24). In another paper I have described the anatomical development of the fruit body (8).

Owing to want of space in these cultures and the consequent approximation of several fruit bodies, compound carpophores are liable to be formed in which three or four distinct ones agglomerate into a single stipe and pileus, the lines of union remaining recognizable.

In this crowded condition some of the sporophores may grow downwards (Fig. 19), though they never do so when space allows.

In one case the fruit bodies appeared as rounded instead of conical protuberances, and eventually had bulbous bases to their stipes (Fig. 25).

The average size of the artificially produced fruit bodies was considerably smaller than those found in nature; in no case did the expanded pileus exceed two inches in diameter. The stipes, too, are rather more slender and elongated. As they were mostly grown in the dark, this was only to be expected. In this connexion a curious feature presented itself. All cultures grown in the dark produced pure white carpophores, which is the prevalent colouring in nature, whereas those grown in the light were invariably dark brown or, at least, a decided fuscous grey, turning somewhat lighter with maturity. Moreover, if when still young the culture was transferred from the light to the dark, or vice versa, the hue changed to that appropriate to the altered conditions. If the transfer was effected at a late stage, however, no appreciable change in tint was observable.

These facts may perhaps be taken to throw some light on the differences in colour noticed by the several authors in the naturally grown fructifications.

The fructifications reached maturity equally well when grown in the dark or in the light, but; on the whole, they were a little less robust when kept entirely in the dark and matured a little less rapidly.

There remains but one more culture to be given special notice. In a bulb flask a bread culture was made in the usual way, but was moistened with a Io per cent. watery solution of glucose and a small quantity of 4 per cent. lactic acid. This was inoculated with a small piece of bread permeated with mycelium, taken from one of the cultures that eleven days later began to fructify. The inoculation was effected on January 18 , and 
the usual precautions to ensure purity were observed. It is important to note that in the parent culture no impurity presented itself at any time, and the subsequent development of normal carpophores of $A$. mucida in it demonstrated that the fungus growing actually was the one desired.

In two days growth from the inoculated section was perceptible, and was of the normal type of white mycelium. Before this had spread further than an inch, however, a new description of growth was seen. The flask had been kept in the light by a window, and a plate of smooth tissue of a light brown colour, rather of the hue of many of the fructifications developed in the light, projected itself above the surface of the mycelium. Other similar cutgrowths appeared alongside the first, and it seemed as if the tissues producing the fruit bodies were unable to form the usual form of erect carpophores, but were giving rise to a series of folds standing out vertically from the surface (Fig. 26). The mass presented an appearance somewhat recalling that of a tremelloid fructification.

On microscopical examination it was found that the inside of the folds consisted of a palisade layer at right angles to its surface entirely resembling the basidial layer of the normal hymenium. Many spores of the normal shape were scattered about, but none connected with the basidia could be seen, nor even, at first, were any sterigmata to be found. After repeated cutting of sections, however, some sterigmata were seen, which in no particular differed from those of basidia on normal fructifications.

This abnormal growth progressed somewhat slowly, and very gradually spread over half of the available area. Meanwhile the mycelium grew out in the opposite direction, and from the latter, on April 8, the first indication of a normal carpophore came to light. Instead of being erect, however, it projected horizontally from the side of a cube of bread. By April 24 it had grown out to a length of $2 \frac{1}{2}$ inches, with the distal $\frac{1}{2}$ inch swollen to a club. This swelling no doubt represented what should have been the cap, but actually no cap was differentiated. The stipe remained prostrate, and the swollen end rested on the bread, where it reverted to vegetative growth. At the base, however, and later on at the apex as well, a mass of incipient carpophores arose (Fig. 27). Some of these secondary fructifications attained a length of $1 \frac{1}{2}$ inches, but none produced a cap visible to the naked eye. Sectioned with the microtome a differentiation into primordial pileus and hymenium could be distinguished. No further progress towards ripening a fully developed carpophore was made, and the fruit bodies drooped and degenerated. Some evidenced a tendency to produce tertiary fructifications a little below the apex (Fig. 28); eventually they also either degenerated or began to grow out into vegetative mycelium.

From all the above-mentioned facts it seems certain that the abnormal fructifications, extraordinary as it may seem, can only be very aberrant 
resupinate forms of Armillaria mucida. Abnormalities of this nature are not altogether unknown in the case of other fungi.

It must be remembered that the inoculation was made from a culture that never showed any trace of impurity and produced normal carpophores, proving its identity. Also, the daughter-culture under consideration produced a mycelium of normal appearance, and on one part of it incipient fruit bodies which entirely resembled those of $A$. mucida appeared, though they failed to mature. Unfortunately, I was unable to separate out the spores from the abnormal fructifications so as to germinate them, nor could I obtain vegetative growth from pieces of the fructification in separate cultures.

In the normal carpophores it was observed that, as laid down by Fayod (7), the spore does not arise apically on the sterigma, but somewhat laterally, and only assumes the central position later on as it approaches maturity (Fig. $29 a, b, c$ ).

\section{INOCULATIONS.}

The experiments carried out to test for parasitic habit were of two descriptions : on living trees in the open and on living and dead twigs in the laboratory.

On November 27 a healthy branch about $2 \frac{1}{2}$ inches in diameter was selected on a sound beech tree, and two holes some eight inches apart were bored to its centre with a centre-bit, which had been previously sterilized by dipping it first in corrosive sublimate and then in absolute alcohol. Spores taken from a carpophore obtained in the neighbourhood were placed in one of the bore-holes only, the other being left intact. Both holes were closed with grafting-wax. A little further along the same branch a small wound just exposing the wood was made and was also infected with spores, and similarly occluded with wax. The branch was cut off on April I 7 , on which date it was quite healthy and full of sap. No infection had taken place at either of the points at which the spores had been placed. Spores were still adhering in a mass to the surfaces of the wounds; most had not even germinated, and those germ-tubes that had appeared had failed to effect an entry into the wood. The section of wood containing the inoculated bore-hole was put in a damp vessel on April 19. By June 5 it was found that hyphae had penetrated about $50 \mu$ into the tissues, which though now dead were still full of moisture. The block was then placed in a dry jar. Sixteen days later, the wood being then comparatively dry, it was ascertained that the hyphae had penetrated much deeper and were far more abundant.

On January II two further inoculations were made on living beech trees. One rather slender branch on each of two healthy trees was picked out. In each case a twig was broken off so as to leave a jagged surface, 
which was then inoculated with a piece of mycelium from a pure culture on bread, on which a carpophore had grown. The wound was bound up with a length of bast that had been previously sterilized in absolute alcohol, which was allowed to evaporate off before binding. As a control, neighbour twigs were also broken off but not inoculated. The twigs were removed on April I 7 for examination. In one case there were no signs of infection; in the other the stub of the twig broken off, half an inch in length, was dead and discoloured throughout, and fungal hyphae could be seen to have penetrated to a depth of about one milimetre into the wood, but nowhere into still-living tissue.

Four beech plants five feet high and of a rather bushy habit were procured and planted out. One of them was inoculated in two places with sections of mycelium grown on bread-on the wound surface where a twig had been broken off, and on a cut on the stem. A control plant was similarly mutilated, but was not infected.

A third bush was grafted at two points with pieces of wood permeated with the hyphae of $A$. mucida taken out of a pure culture, and a control was cut in the same manner, but not grafted. All four inoculation spots were bound with bast steeped in alcohol, and were then smeared over with grafting-wax.

They were cut off on June 22, when it was found that no infection of living tissues had taken place. The stub left on breaking off a twig had died and was dry and discoloured, and in this alone had hyphae penetrated, but only as far as the point to which the tissues had died.

At the end of November some beech sticks, $\frac{3}{4}$ to I inch in diameter, were brought in from Windsor Park while still quite fresh and green. The cut ends were occluded with sealing-wax to hinder the evaporation of the moisture contained, and the sticks were inoculated with spores at places where the bark had been cut away sufficiently to discover the wood. They were then placed in a closed sterilized jar. On March I 3 all were dead, no trace of green being revealed on incisions being made. One was cut up, but no signs of penetration by the hyphae could be detected. The remaining twigs were placed in a dish on moist earth, and on examination on May 22 were found to be grown through and through with hyphae.

Two other twigs, each with a side shoot and a bud attached, were inoculated with spores in incisions, and were placed in a jar of water. Early in February the buds had opened and fresh buds had formed, so that both twigs bore leaves, and consequently their tissues were still living. On March 16 one of the twigs had lost its leaves, and its tissues were found to be dead, but the leaves of the other were still fresh. In neither case had infection taken place. The inoculated spots of the dead one were then cut off, and the exposed surfaces were sterilized in the flame. The whole twig was then rubbed over with absolute alcohol, and after being allowed to dry 


\section{Fischer. - The Biology of Armillaria mucida, Schrader.}

was reinoculated with pieces of mycelium from a pure culture, in incisions extending to the wood. It was then placed in a vessel of water standing in a stoppered jar. In a short time white mycelium in abundance appeared on the outside of the twig and soon spread around, attaching the twig to the side of the vessel. On microscopical examination it was ascertained that the hyphae had penetrated right to the centre of the wood, and no starch reaction was obtained with iodine (the fungus absorbs the starch, as will be seen later). In places the mycelium had found its way between the epidermis and the cortex, and had separated the two in waved lines, raising the epidermis in a blister-like manner.

The two last described experiments were repeated with the same results, which seems to show that the fungus is unable to effect an entry so long as a certain proportion of moisture in the wood is exceeded, with a corresponding lack of air. This is quite in accord with the results of Münch's researches with Nectria ditissima, Cerastomella coerulea, and other facultative wood parasites (18).

On sterilized thin unbarked beech twigs, mycelium inoculated from a pure culture grew very rapidly, entering the wood at the cut surfaces. An abundant dense, pure white mycelium overspread the twigs and extended all round and over the inside of the glass receptacle, and eventually it gave rise to two carpophores.

\section{DedUCtions as to PARASITISM.}

We can now consider how all the experiments described above affect the question of the parasitic nature of Armillaria mucida. We have seen that attempts to grow the fungus as a parasite have failed, but on the other hand it was readily cultivable as a saprophyte on several nutritive media. It could also be grown on dead beech wood, on which it produced fructifications. In fact, the evidence so far available nowhere records the appearance of fruit bodies on living wood, though it is to be seen on dead parts of living trees. It is possible that it is a facultative parasite demanding specially favourable conditions to enable it to attack living tissues. It seems possible that it must first develop saprophytically and then, after a start, during which it has gained vigour, is able to enter upon a parasitic existence. These conditions would be secured at a point where a branch has broken off and the surface tissues have died from loss of moisture, but as yet we have no certain evidence in support.

It may be noted, also, that no one has recorded the occurrence of the fungus on young beech plants. 


\section{Action of the Fungus on the Tissues.}

Methods.-In order to investigate the action of the hyphae on the wood of its host the following methods were employed.

Diseased wood brought in from Windsor Park was sawn into convenient sections and fixed in one of the following solutions :-

Merkel's solution.

Flemming's weak solution.

Absolute alcohol.

Picric acid.

Sections were cut freehand and tested with iodine, chlor-zinc-iodine, phloroglucin, alkalin, \&c., and were stained by the methods detailed below.

At all stages sections of sound wood were treated in the same manner for comparison.

The stains employed were :-

Gentian violet and Congo red, as described by Biffen (1).

Ruthenium red and methyl green, first soaking in a solution of 75 per cent. alcohol and 25 per cent. hydrochloric acid and washing in 50 per cent. ammonia.

Safranin and Hoffmann's blue. With this stain after many trials the most satisfactory procedure was found to be the following: The sections were placed in safranin for fifteen minutes and then washed rapidly in 50 per cent. alcohol. They were then left in the Hoffmann's blue for from fifteen to twenty minutes and then washed in water. They were then passed rapidly up to absolute alcohol, and through xylol, and mounted in canada balsam.

Lastly, the diamant fuchsin and light green method was tried and gave the best results, especially for following the course of the hyphae in the tissues.

\section{Disorganization OF THE TISSUES.}

The portions attacked can be recognized by the discolouration of the wood, which assumes a dark grey hue with the large medullary rays standing out unchanged (Figs. 30 and $3 \mathrm{I}$ ). Just as Biffen observed with Bulgaria polymorpha (1), the medullary rays seem to withstand the attack longer, but eventually they too succumb.

The hyphae apparently disintegrate after they have done their work, for where the wood had undergone considerable change (as described below), few or no hyphae were to be met with, whereas in places in which the hyphae were abundant the decomposition had hardly begun. This can be easily seen by comparing Figs. 32 and 33 . 


\section{Fischer.-The Biology of Armillaria mucida, Schrader.}

The tests applied showed that there was an early disappearance of the starch, followed by a gradual delignification of the secondary layers of the cell-walls of the wood. These layers become swollen and detached from the middle lamellae, and, owing to the want of space in the lumina in their expanded condition, they are curled up and contorted (Fig. 34). Gradually these disorganized tissues decompose and are absorbed by the hyphae, until only the middle lamellae are left (Fig. 33). In this state the wood is full of air and has become soft and lighter in colour.

The early stages tested with iodine or chlor-zinc-iodine gave no starch reaction. At a later stage with phloroglucin results similar to those obtained by Marshall Ward in the case of Stereum hirsutum (28) presented themselves. The middle lamellae stained a deep bright pink, the layers next to them were of a lighter pink, and the innermost swollen layers remained colourless, showing delignification from the lumen outwards. The cells of the medullary rays and of the wood parenchyma retained their lignin intact for a longer period, showing up in the advanced stages more or less bright pink in the midst of colourless fibres, vessels, and tracheids.

In the advanced stages the secondary layers of the cell-walls before their absorption gave a cellulose reaction with chlor-zinc-iodine, demonstrating the reduction to cellulose. This was too general and too complete to be referred to want of lignification as suggested by Potter (20) ; moreover, sound wood similarly tested gave no violet colour.

Evidence in the same direction was obtained with the gentian violet and Congo red stain. The lignified walls took on a blue stain, and those converted to cellulose coloured pink with the Congo red. The reactions, however, were not so very definite as the results obtained by Biffen.

With ruthenium red and methyl green the middle lamellae stained a cherry red, and the secondary layers either remained colourless, especially where much swollen and contorted, or took on a light green tint.

After the disappearance of the starch, products of decomposition of a brown colour are present in the cells of the medullary rays and of the parenchyma. Tested with ferrous sulphate they showed no trace of tannin, and the alkalin test betrayed no oil.

In the cubes of beech wood on which the mycelium had grown in pure culture, no structural change could be detected after two months, and no chemical alteration was revealed by the phloroglucin test. After the lapse of five months, however, the secondary walls were affected. With the diamant fuchsin and light green stains the structural changes described above for advanced stages of attack were verified; the detachment and partial disappearance of the secondary layers being evident.

The course of the hyphae in the wood can be followed in the sections stained with the diamant fuchsin and light green method (Fig. 35). This 
stain colours the walls that are still lignified a light pink, with the middle lamellae standing out a darker shade, and the secondary layers remain uncoloured or stain green. The hyphae are stained olive green.

With safranin and Hoffmann's blue the host tissues are pink and the hyphae blue.

The hyphae may pass from cell to cell through the pits, but also bore their own way through the intact walls. The diameter of the hyphae varies considerably, ranging from 2 to $5 \mu$.

Pieces of a diseased branch that actually bore carpophores of A.mucida, and the wood of which was in an advanced stage of decay, were ground up into a powder, which was left to soak in $5^{\circ}$ per cent. glycerine for about five weeks. In the filtrate obtained from this, small pieces of sound beech wood were immersed for $2 \frac{1}{2}$ months. No structural change was visible, but treated with Schultz's solution, though the starch was found to be practically intact, there were distinct signs of delignification of the secondary layers of the cell-walls, which were stained a more or less deep violet to pale lilac, according to the degree of decomposition, with the middle lamellae yellow. In places, too, the secondary layers were detached from the middle lamellae and contorted, much as was the case in the diseased wood described above, though not to the same extent.

I feel justified, therefore, in concluding that the fungus secretes an enzyme, or enzymes, capable of reducing the starch and of reconverting the xylem to cellulose.

\section{Remedial and Protective Measures.}

Whatever the eventual conclusions as to the parasitic nature of A. mucida may be, it is certain that it causes serious detriment to beech timber, rendering it unfit for anything but fuel of a poor quality. It is possible that it is not a parasite at all, but it is none the less a foe of the beech forest and, like some other xylophile fungi, may require a preparation of the tissues by other organisms or by special conditions before it can avail itself of the nutriment they afford. Therefore, it is advisable to consider what precautions can be adopted to prevent its gaining an entrance into beech trees, and what can be done to eradicate it once it has established a footing.

The taking of active steps against fungoid diseases must ever be controlled by the question of cost. In maladies such as the one under consideration it too often happens that the necessary expenditure is out of proportion to the benefit to accrue. Nevertheless, it will be readily conceived that where beech is grown commercially this fungus, given suitable conditions, might inflict such losses that heavy expenditure on its eradication, and in subsequently protecting the forest against its inroads, would be 


\section{Fischer.-The Biology of Armillaria mucida, Schrader.}

amply justified, and that failing drastic action some other species of timber tree would have to be grown in its place.

Prevention is better than cure, and in the case of small parks and avenues it is worth while to protect the trees against the entry of the disease. From its nature it is obvious that the fungus can enter a tree only by means of its spores, and these must alight on a wound from which the bark has been completely removed, so that they can reach the mature wood. Therefore, all wounds that give this opportunity should be promptly painted over with an antiseptic ; one of the compounds of tar is most suitable. Tubeuf (27) has shown that the normal formation of wound tissue is not a sufficient protection, hence the necessity of an antiseptic which, of course, will also keep the wound secure from the attacks of other timberinfecting fungi.

Where the disease has established itself all diseased branches must be cut off and destroyed, and the exposed surfaces must be painted over as before. Care must be taken to cut off the limb at a point which will assure the removal of all trace of diseased tissue. For this purpose, where there is any doubt, the aid of the microscope should be called in.

This eradication may in some cases demand the sacrifice of the whole tree. As an attacked tree may live for many years, owners of ornamental parks may not be prepared to fell. In that case the tree must be kept under watchful observation, and the carpophores must be destroyed as soon as they appear and before they can ripen and shed their spores. This precaution, if strictly enforced, will preclude infection from diseased trees within the property, but will not insure against infection from outside by wind-borne spores. In any case decaying beech stumps or timber should on no account be left lying about, since the fungus may live saprophytically in the wood and develop its fruit bodies, and become a centre of infection.

When one remembers that a single spore may infect a tree, and that according to Buller's calculation (4) a single fruit body of Polyporus squamosus, 250 sq. centimetres in area, produces II, II 2,500 spores, the importance of a careful watch for the appearance of the fruit bodies will be realized, if one desires to keep the trees free of the disease.

In forests of considerable extent such measures cannot well be applied. Here, the manager must content himself with removing, as far as possible, all diseased trees and stems exhibiting wounds at the periodical fellings. Also, felled timber must not be left lying in the forest. But these are the platitudes of Forest Science, and no stress need be laid on them here. 


\section{SUMMARY.}

I. Armillaria mucida can be grown saprophytically on various substrata : bread, dead beech wood and twigs, jellies of beer-wort, meat and malt extract, \&c.

2. The spores germinate at once and abundantly in water and prune juice as well as on the above media.

3. The attempts to infect living beech wood failed, and no proof of its alleged parasitism can be preferred.

4. The time elapsing between the sowing of the spores to the ripening of the carpophores in pure cultures varied from 5 I to 109 days.

5. The sporophores produced in the pure cultures were identical with those found in nature on beech trees, but the average size was considerably less, and the spores too were somewhat smaller, but were nevertheless fully capable of germination.

6. No secondary spore forms were obtained.

7. Clamp connexions were observed.

8. The fungus secretes enzymes which liquefy gelatine, dissolve starch, and reduce lignin to cellulose.

9. The products of decomposition contain neither tannin nor oil.

Io. The preventive measures consist in occluding wounds on the trees with an antiseptic.

II. The remedial steps involve the removal and destruction of diseased parts and of the sporophores before they reach maturity.

I desire here to acknowledge the very great assistance I have received from Professors J. B. Farmer, F.R.S., and P. Groom, D.Sc., who suggested this research, and to express my sincere thanks for much kindly advice, many valuable suggestions, and a great deal of instruction tendered by them. My thanks are also due to Mr. M. Wilson, B.Sc., and to Mr. F. J. F. Shaw, B.Sc., for unfailing kind assistance. The latter gentleman also very kindly took the photograph reproduced as Fig. 23 . Finally, I have to acknowledge the kindness of Dr. Somerville Hastings, F.R.C.S., who gave permission for the reproduction of two admirable photographs (Figs. I and 2) of A. mucida, which have already been published in Messrs. Gowans and Gray's excellent booklet 'Toadstools at Home'.

\section{LITERATURE.}

1. Biffen : On the Biology of Bulgaria polymorpha. Annals of Botany, xv, Igor.

2. Brefeld, O. : Untersuchungen aus dem Gesammtgebiet der Mycologie, Heft viii, 1899, p. 54.

3. - Ibid., Heft xiv, 1908.

4. Buller, A. H. R.: The Biology of Polyporus squamosa. Jonrnal of Economic Biology, i, part 3, I906. 


\title{
534 Fischer. - The Biology of Armillaria mucida, Schrader.
}

5. Cooke, M. C.: Handbook of British Fungi, I87I, p. 20.

6. : Fungoid pests of cultivated plants. 1906, p. 2 I 2.

7. Fayod, A.: Prodrome d'une histoire naturelle des Agaricinées. Annales des Sciences naturelles, $7^{\circ}$ série, ix, 1889 .

8. Fischer, C. E. C. : The Development of Armillaria mucida. Annals of Botany, July, I909.

9. Frank, A. B. : Krankheiten der Pflanzen. I88o.

10. FrIES : Systema mycologicum, i, I82I, p. 28.

11. Gautier: Les Champignons. I 884 .

12. Gillot and LUCAUd : Catalogue raisonné des champignons supérieurs. I $89 \mathrm{I}$.

13. Lambotte: Flore mycologique de la Belgique, i, 1880, p. 46.

LuCAUd, Gillot and. Vide 12 supra.

14. MASSEe, G. : British Fungus Flora, iii, 1895, p. 23.

15. : A Textbook of Plant Diseases. I889.

16. McIlvaine, C.: One thousand American Fungi. 1902.

17. MÜNCH, E.: Die Form der Hausschwammsporen. Naturwissenschaftl. Zeitschrift für Land- und Forstwirtschaft, v, No. I 2, 1907, p. 616.

18. - Untersuchungen über Immunität und Krankheitsempfänglichkeit der Holzpflanzen. Naturwissenschaftl. Zeitschrift für Land- und Forstwirtschaft, vii, 1909; no. I, p. 54 ; no. 2, p. 87 ; no. 3 , p. I 29.

19. Patouillard: Tabulae analyticae fungorum, i886, p. I8I.

20. Рotter, M. C. : Cellulose in the xylem of woody stems. Annals of Botany, xviii, 1904.

21. Prillieux, Ed.: Maladies des Plantes Agricoles. 1897 .

22. RABENHORST : Kryptogamen-Flora, Band i, Abth. I, p. 829.

23. SACCARDO : Sylloge Fungorum, v, p. 85.

24. Schrader: Spicilegium Florae Germanicae. I 794.

25. Sorauer, P.: Handbuch der Pflanzenkrankheiten, ii, I9a6, p. 393.

26. Tubeuf, C. von: Pflanzenkrankheiten. I895.

27. - Ueber normale und pathogene Kernbildung etc. Zeitschrift für Forst- und Jagdwesen, I889.

28. Ward, H. Marshall : Biology of Stereum hirsutum. Transactions of the Royal Society, clxxxix, I897.

\section{EXPLANATION OF PLATES XXXVII AND XXXVIII.}

\author{
Illustrating Mr. Fischer's paper on Armillaria mucida.
}

Figs. 1,2 , and 24 are from photographs. Figs. 3 to $16,29 a, b, c$, and 32 to 35 from drawings by the author with the camera lucida. Figs. 17 to 23,25 to 28,30 and 31 from freehand drawings hy the author.

\section{PLATE XXXVII.}

Figs. I and 2. Armillaria mucida on beech. Photographs by Dr. Somerville Hastings, F.R.C.S. I $\times \frac{1}{10}::^{2} \times \frac{1}{2}$.

Iig. 3. Collapsed, boat-shaped dry spores. $\times$ about 475 .

Fig. 4. Turgid spherical spores. $x$ about 475 .

Fig. 5. Spores from fruit body grown in pure culture. $\times$ about 475 .

Fig. 6. Germinating spores. $x$ about 260.

Fig. 7. Section from stipe putting out new hyphae in jelly. $\times$ about 100 .

Fig. 8. Germ tube and vegetative growth from basidium. $a$. Germ tube from spore; $b$, much branched hypha from basidium. $\times$ about 475 .

Fig. 9. Multi-septate hypha grown out of a basidium. $x$ about 475 .

Fig. 10. Hypha in moist jelly. $x$ about 100. 
Fig. I I. Hypha in drying jelly. $x$ about 100.

Fig. I 2. Hypha in jelly. $x$ about 300 .

Fig. 13. Curled hypha in jelly hanging drop. $x$ abont 400.

Fig. 14. Clamp connexion. $x$ about 700.

Fig. 15. Clamp connexion on a hypha from a basidium. $x$ about 475 .

Fig. $16 a, b, c$. Hyphae breaking up into rods-oidia? $\times$ about 475 .

Fig. 17. Group of incipient carpophores on bread. $x$ about 1 .

Fig. 18 . The same 24 hours later. $\times$ about $\frac{1}{1}$.

Fig. 19. The same 24 hours older than Fig. 18. $x$ about $\frac{1}{1}$.

Fig. 20. The same 48 hours older than Fig. 19. $\times$ about 1 .

Fig. 21. The same 24 hours older than Fig. 20. $x$ abont $\frac{1}{1}$.

\section{PLATE XXXVIII.}

Fig. $22 a$ and $b$. The same carpophore as in Fig. $2 \mathrm{I}, 24$ hours later. Veil much stretched. $x$ about $\frac{1}{1}$.

Fig. 23. Mature carpophore. $\quad x$ about $\frac{1}{1}$.

Fig. 24. Group of carpophores grown on a pure culture of bread. $\quad x$ about $\frac{1}{4}$. Photograph kindly taken by Mr. J. F. J. Shaw, A.R.C.S.

Fig. 25. Young carpophores grown in the light; dark brown with bulbous bases. $\times$ about $\frac{1}{1}$.

Fig. 26. Abnormal resupinate fructification. $x$ about $\frac{1}{1}$.

Fig. 27. Aberrant undeveloped prostrate carpophore with secondary carpophores arising on basal portion of stipe. $x$ about $\frac{1}{1}$.

Fig. 28. The same 30 days later. Secondary carpophores arising at apex, and indications of tertiary ones near apex of two of the secondary carpophores. $\quad x$ about $\frac{1}{1}$.

Fig. $29 a, b, c$. Basidia showing sterigmata and development of spores. $\quad \times$ about 475 .

Figs. 30 and 31 . Discoloration of wood. $x$ about 1 .

Fig. 32. Hyphae in the vessels, cell-walls as yet but little affected. $\times$ about 475 .

Fig. 33. Advanced stage of attack, hyphae have disappeared and practically middle lamellae only remain. $x$ about 475 .

Fig. 34. The secondary layers of cell-walls detached from middle lamellae and swollen and contorted. $\times$ about 360 .

Fig. 35. Hyphae in cells of large medullary ray. $x$ about 475 .

\section{Imperial College of Science and Technology, South Kensington,} June, 1909 . 
Annals of Botany
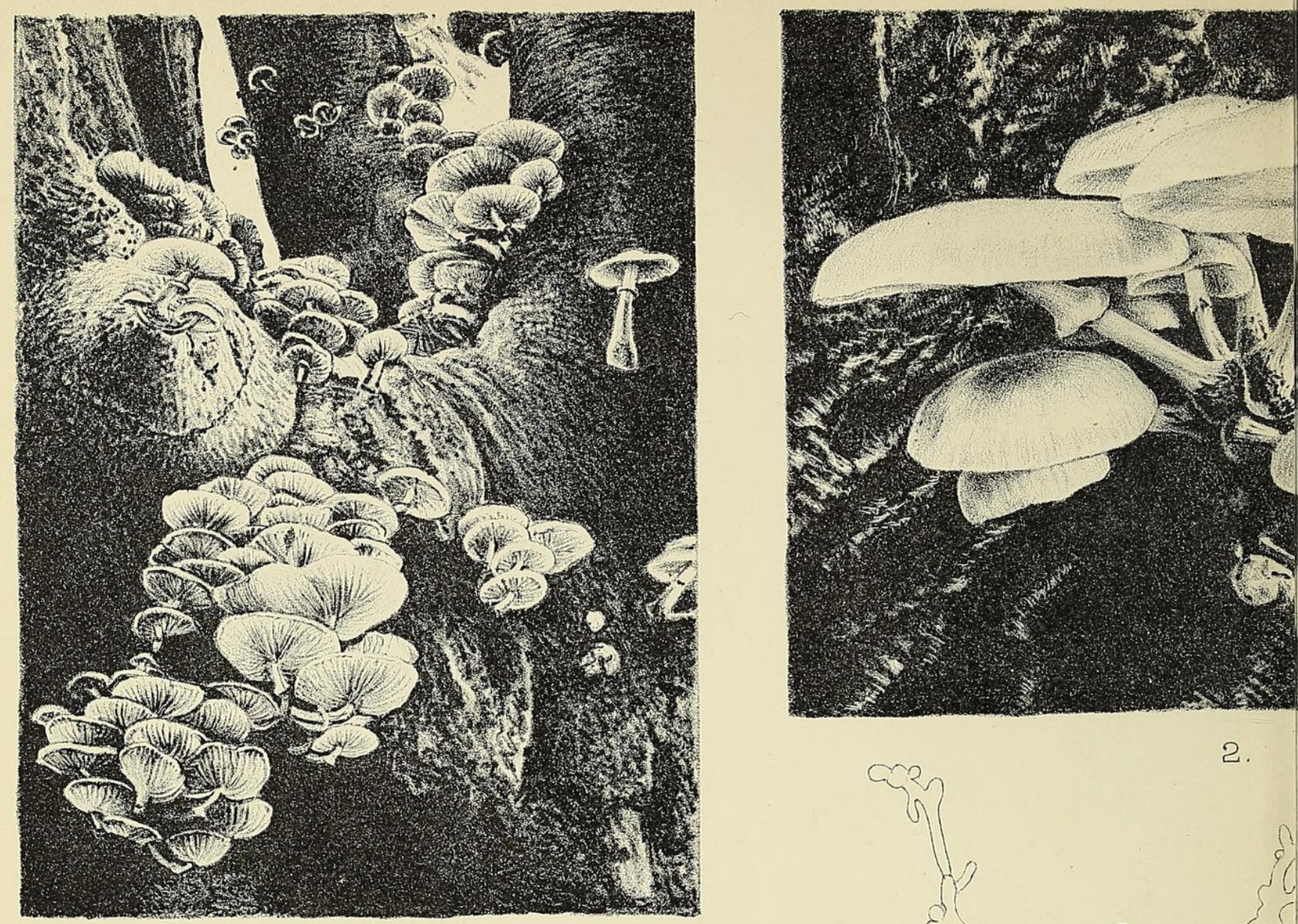

1

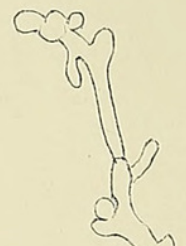

2.

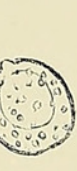

(1) 3 .

$\rightarrow(0)$

4

6.

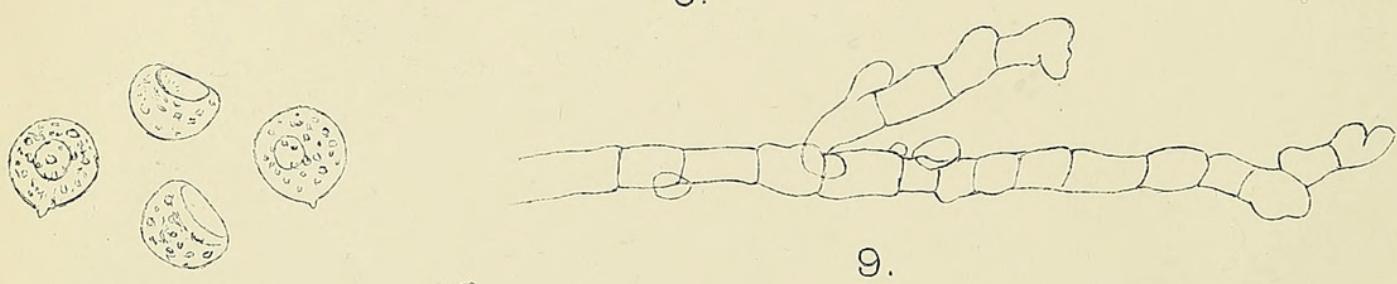

5.

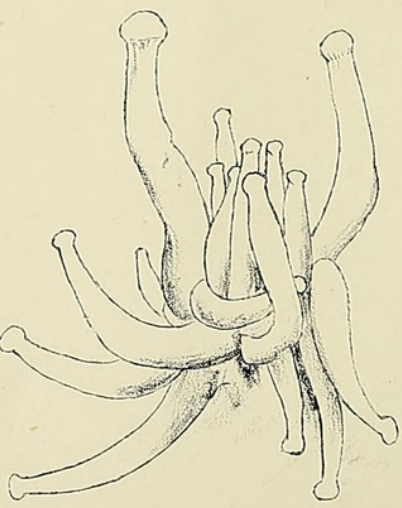

8.

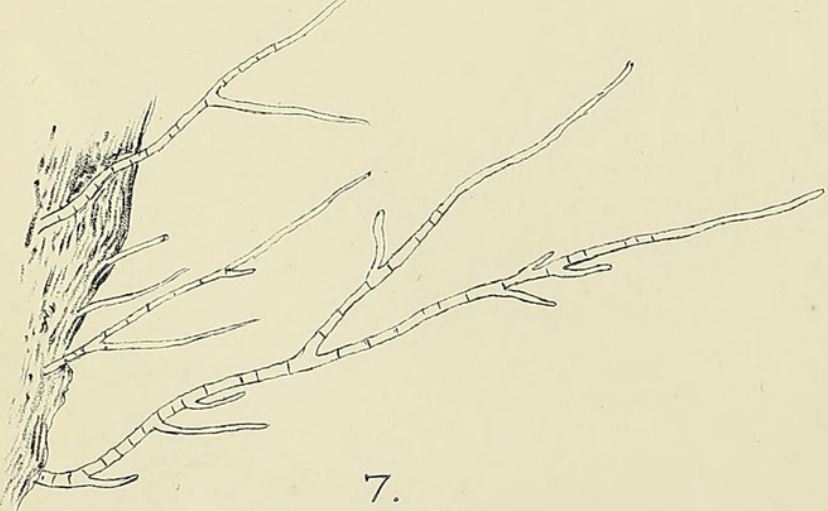



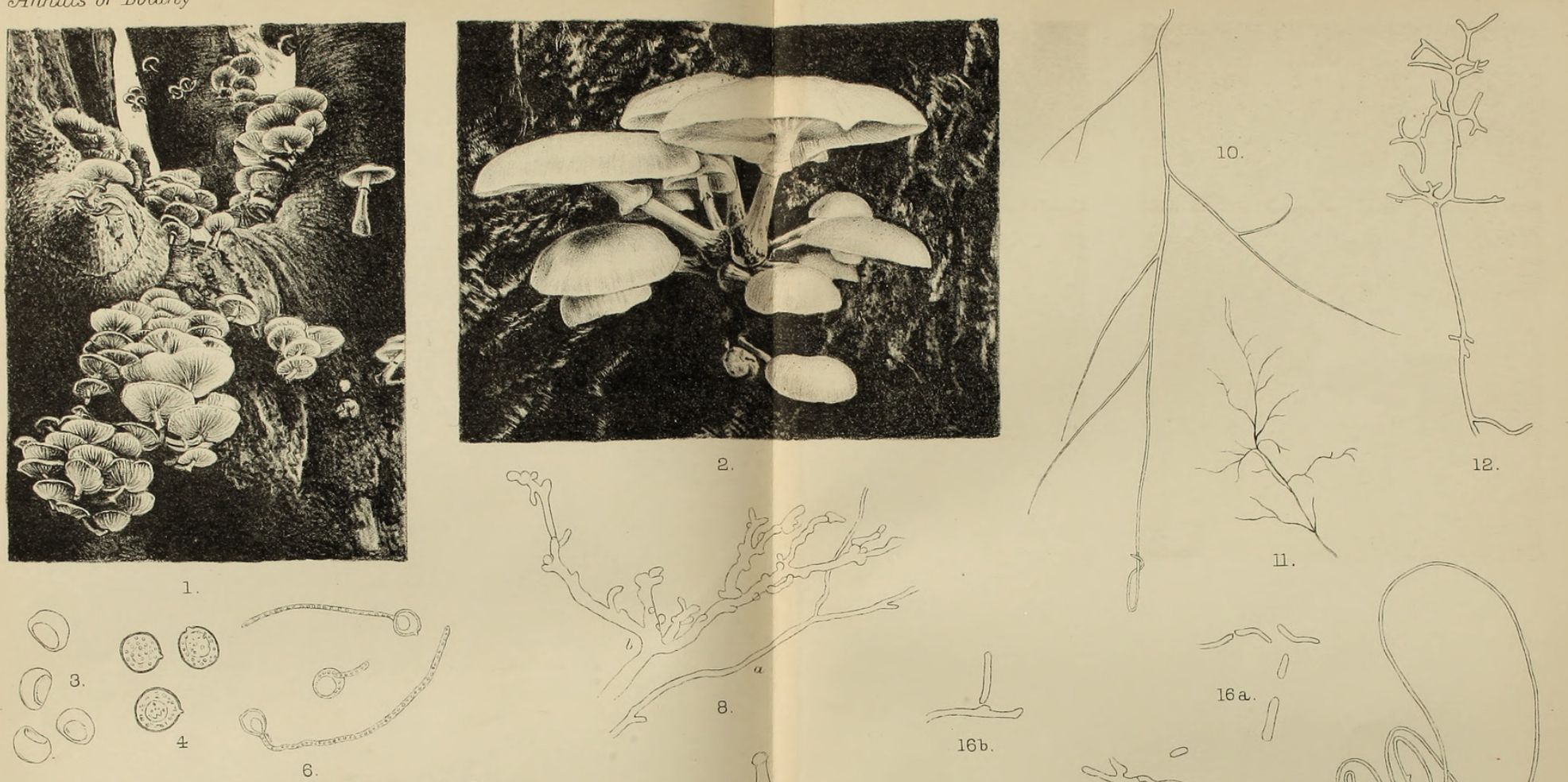

(ivi)
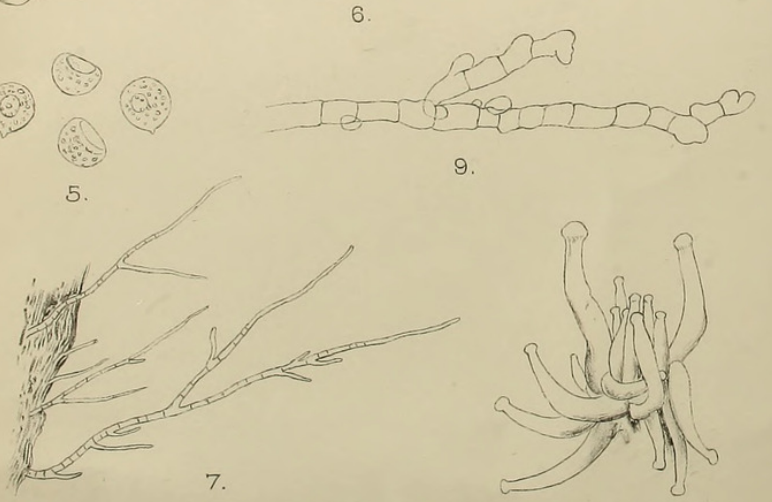

19
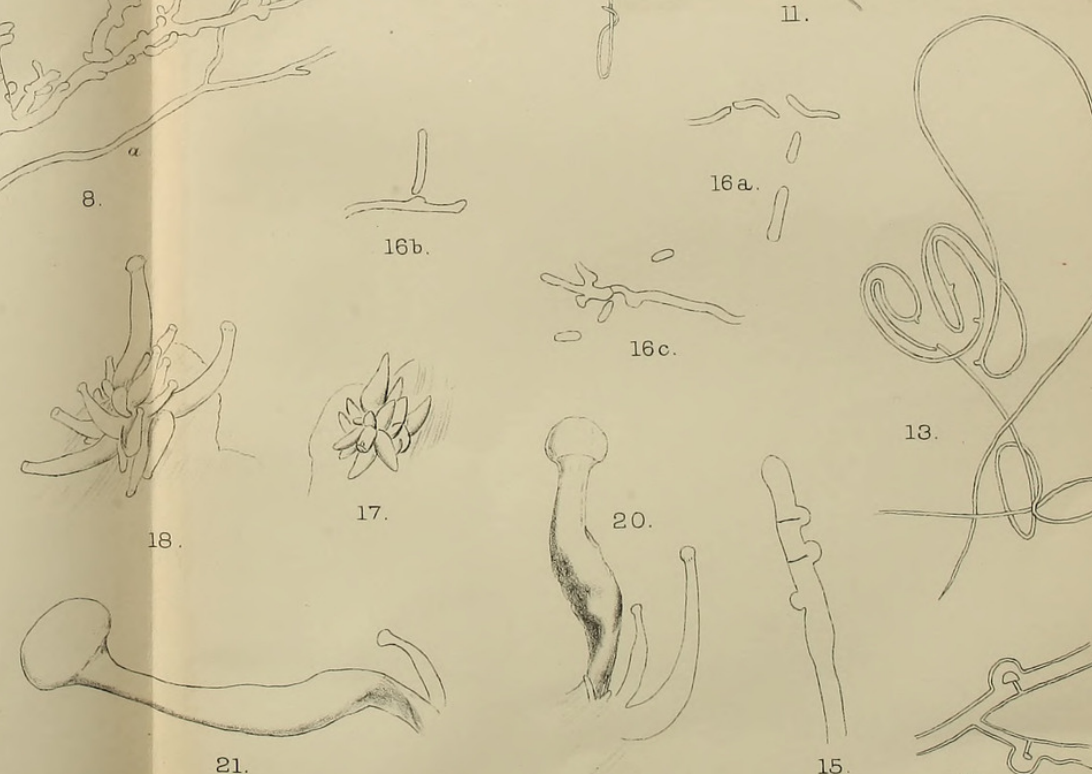

FISCHER - BIOLOGY OF ARMILLARIA MUCIDA. 

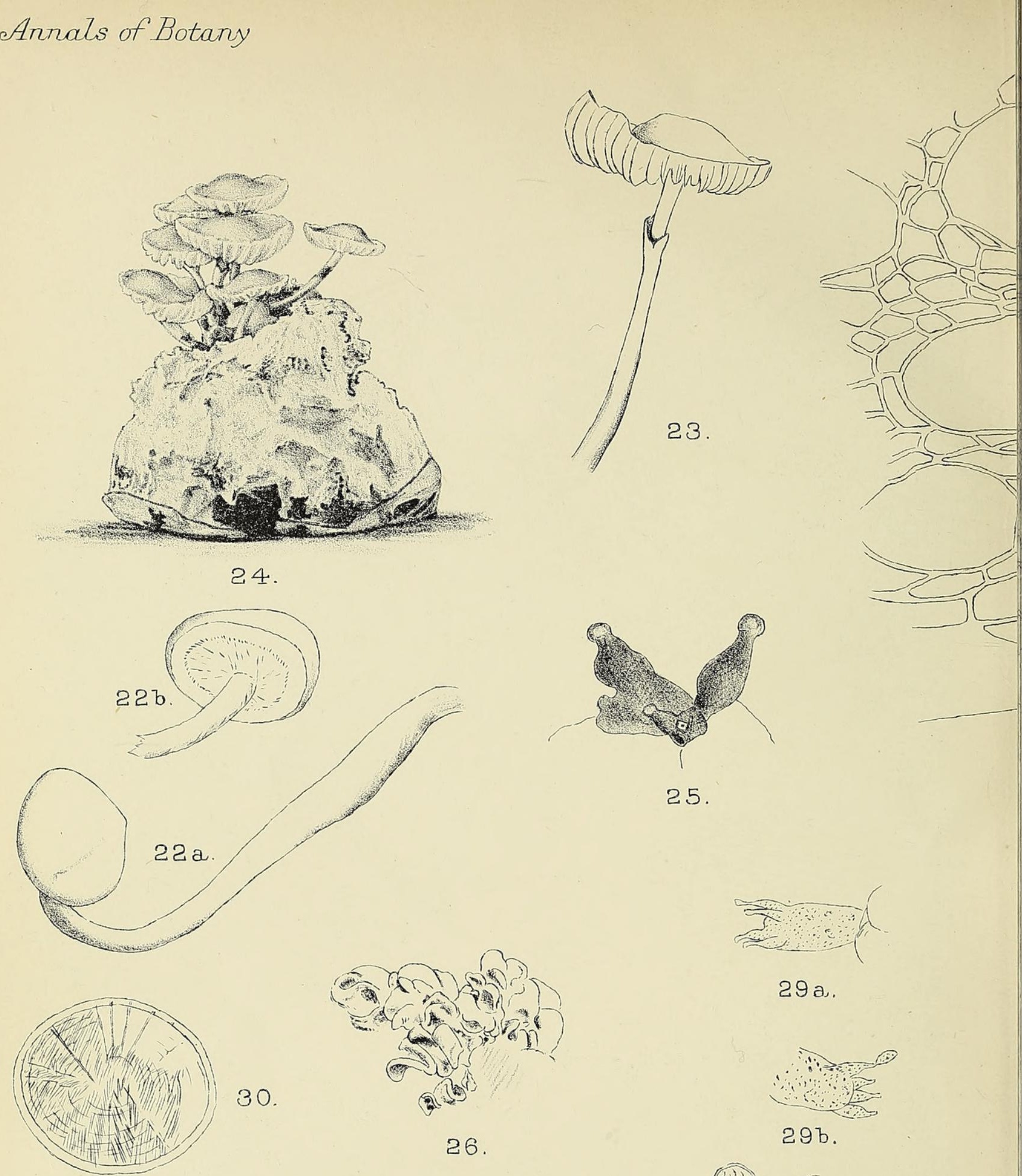

26.
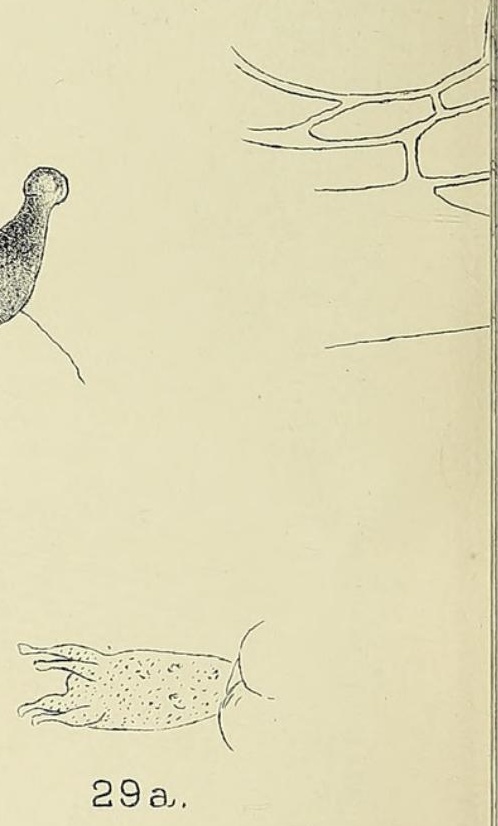

30.
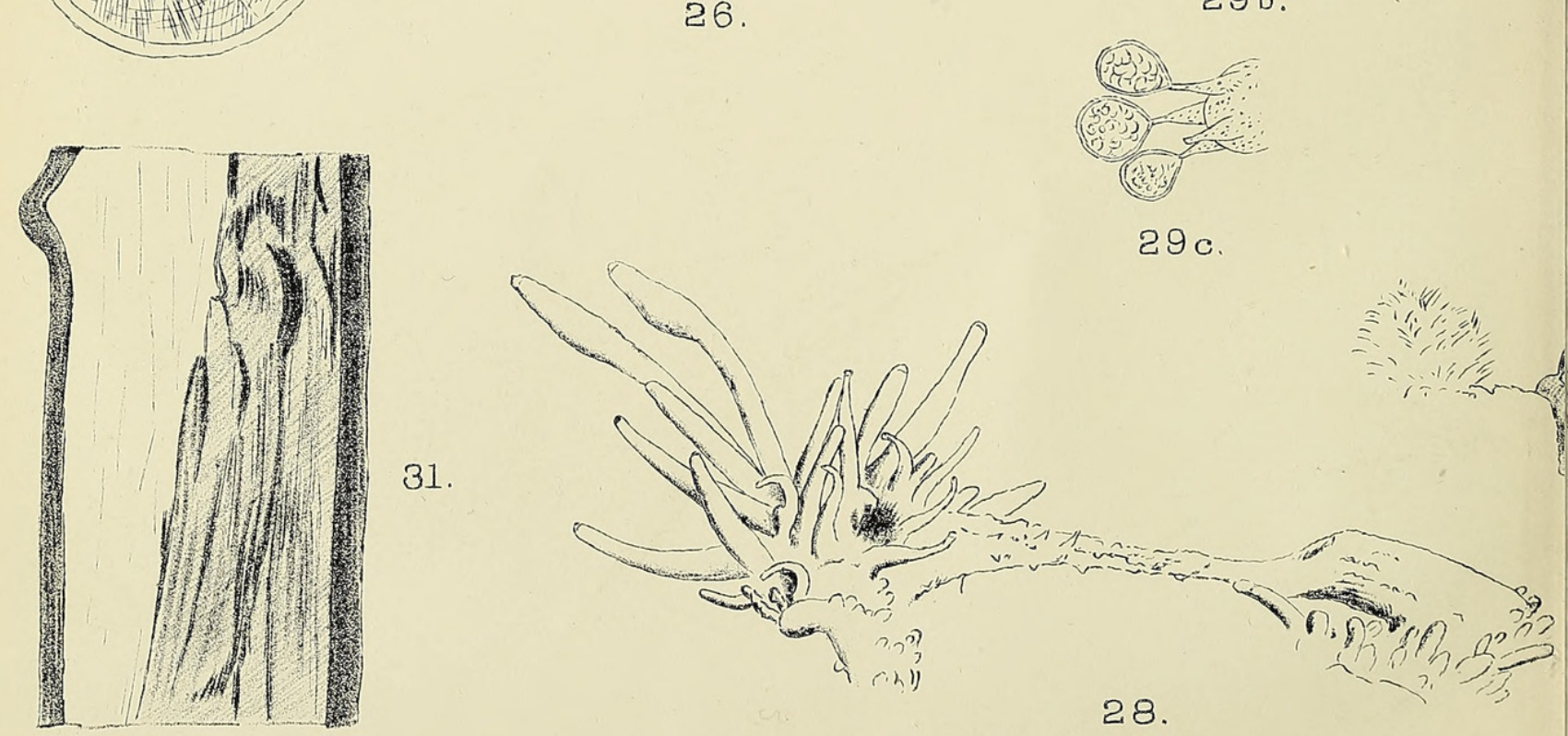

28.

FISCHER - BIOLOGY OF ARMILLARIA MUCIDA. 

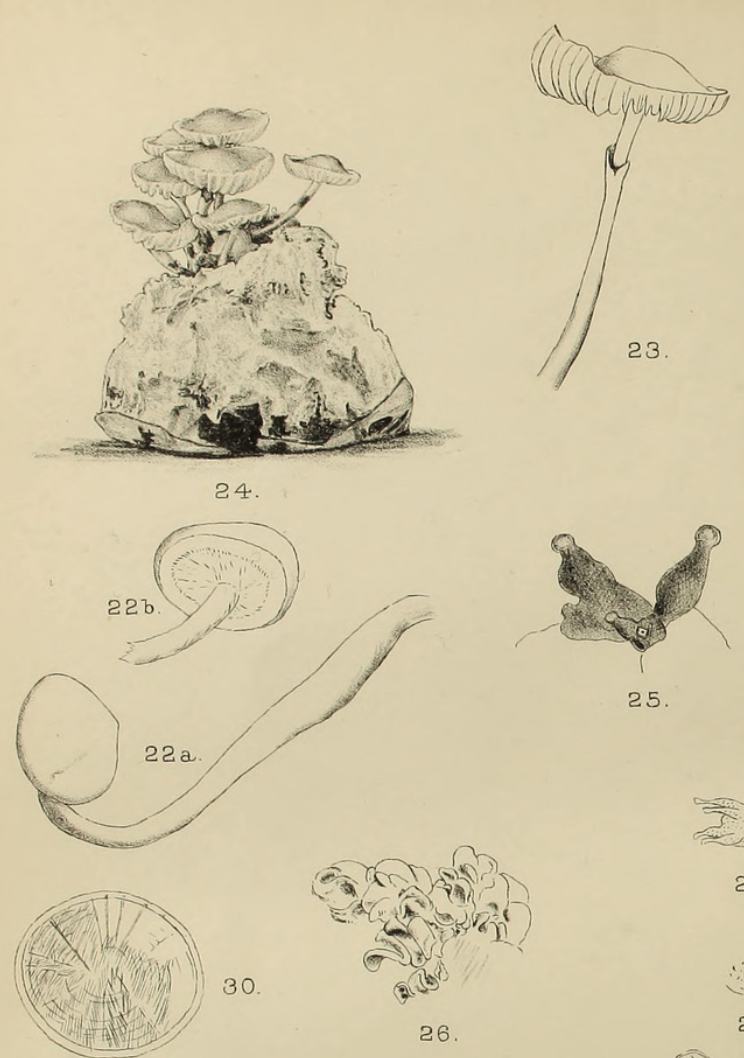

25.
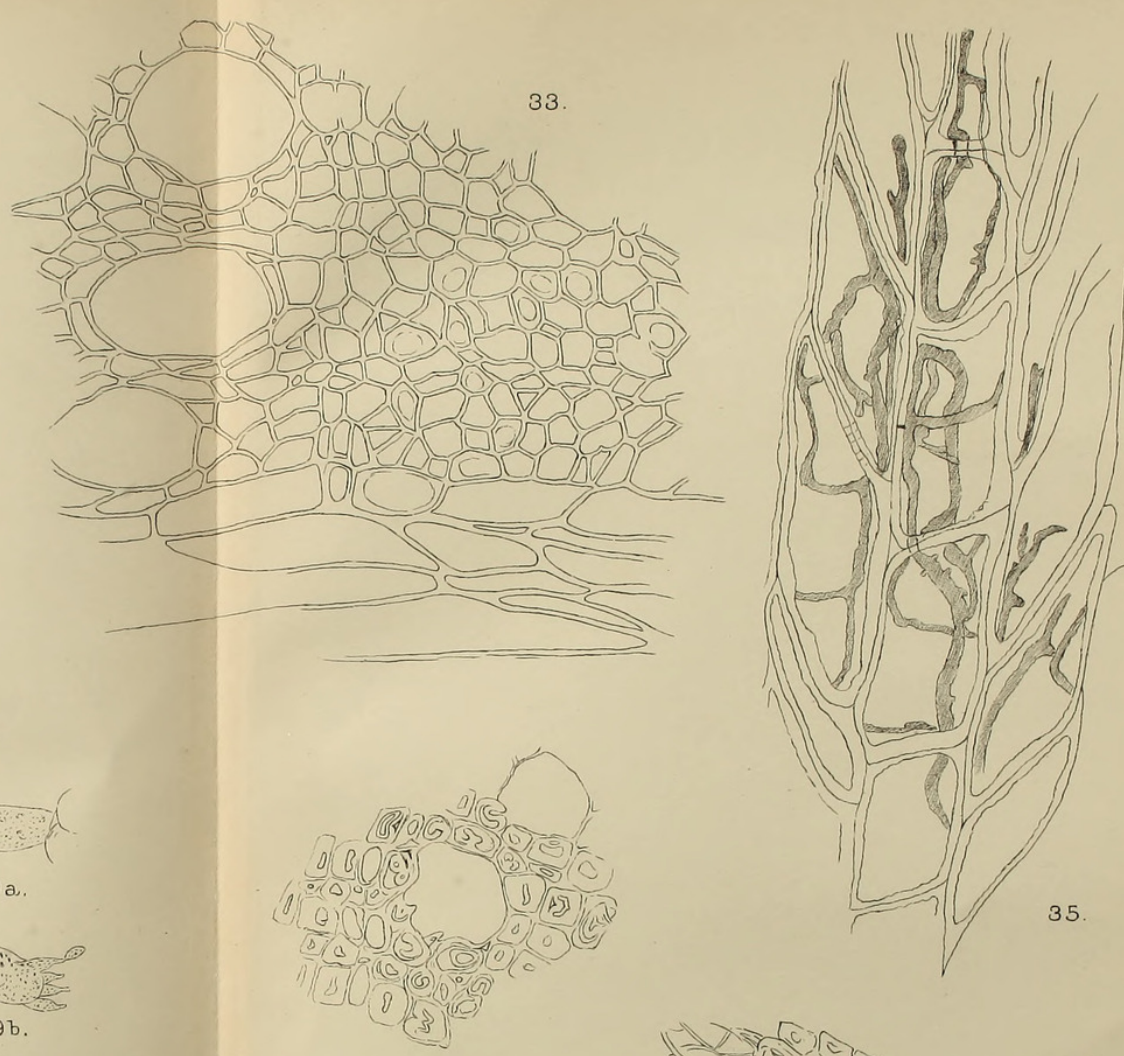

35.
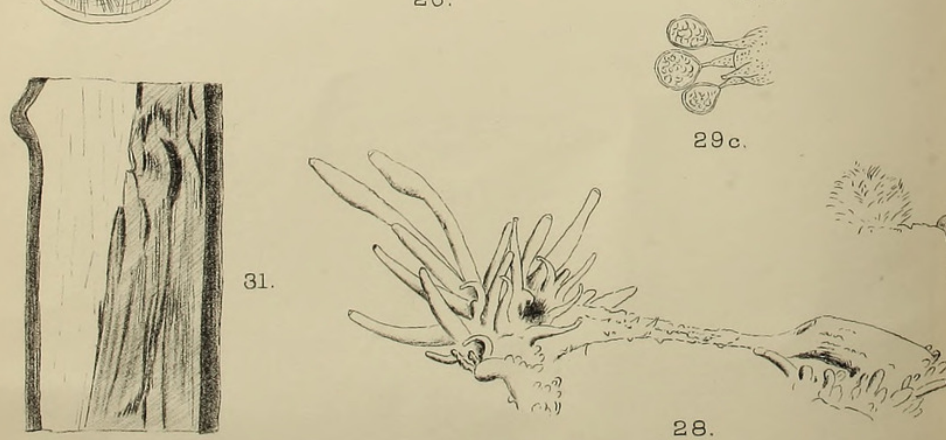

28.

32

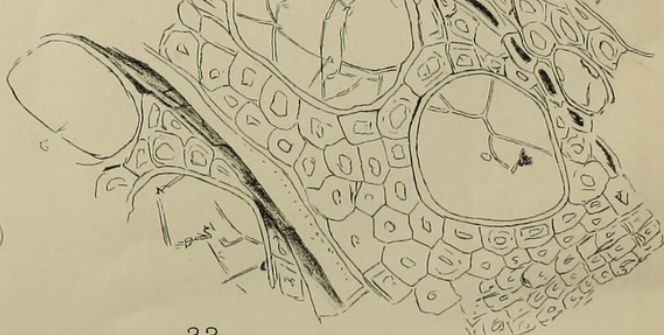




\section{$2 \mathrm{BHL}$ Biodiversity Heritage Library}

Fischer, Cecil Ernest Claude. 1909. "The biology of Armillaria mucida, Schrader." Annals of botany 23, 515-535.

https://doi.org/10.1093/oxfordjournals.aob.a089236.

View This Item Online: https://www.biodiversitylibrary.org/item/236540

DOI: https://doi.org/10.1093/oxfordjournals.aob.a089236

Permalink: https://www.biodiversitylibrary.org/partpdf/318971

\section{Holding Institution}

Smithsonian Libraries

\section{Sponsored by}

Biodiversity Heritage Library

\section{Copyright \& Reuse}

Copyright Status: Not in copyright. The BHL knows of no copyright restrictions on this item.

This document was created from content at the Biodiversity Heritage Library, the world's largest open access digital library for biodiversity literature and archives. Visit BHL at https://www.biodiversitylibrary.org. 